\title{
Editorial
}

\section{Nervous systems: How to control the risks of complex systems in civil and military areas?}

Modern technology gives us the opportunity to use and measure data that we could not detect with our own sensory organs. As these data require adequate, sometimes rapid responses, we may have to make decisions under stress, lacking sensitivity or the instincts for reacting.

For example, we have no sensory organs for radioactivity. When a good surveillance system sounds an alarm, very different reactions are plausible. For instance, at the Hanford nuclear reactor, a worker was contaminated by radioactive zinc. The amount was within the limits allowed. The contamination had occured a few hundred miles away from the Pacific Ocean, from eating an oyster. But the contamination was originally caused by the waste water of Hanford! Two totally different emotional reactions, for and against nuclear power, may ensue. Both are rational and scientifically motivated:

(a) how horrible: apparently the entire landscape downstream is polluted. We are all endangered!

(b) how fantastic: the amount of radioactivity is insignificant, but what precision of measurement!

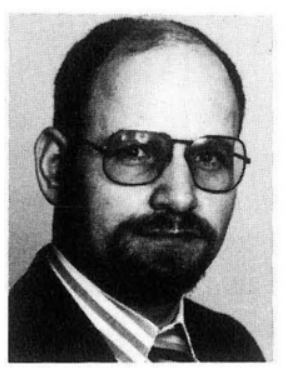

Philipp Sonntag is a member of the International Institute for Comparative Social Research, Wissenschaftszentrum Berlin. He is a physicist and a social scientist with a PhD in physics from the Technical University of Hannover. Prior to his present position he investigated catastrophies and ecological systems with C.F. von Weizsäcker at the Max-Planck-Institute for Research on the Conditions of Life in the Scientific-Technical World. In his recent book: "Verhinderung und Linderung atomarer Katastrophen" (Prevention and Alleviation of Atomic Catastrophies) he evaluates different ways toward preventing atomic catastrophies and investigates the experiences of Hiroshima and Nagasaki in order to estimate the complexity of impacts on a society.

North-Holland Publishing Company

Human Systems Management 3 (1982) 1-3
We have the situation technically well under control. Society reacted to these problems by establishing more and stricter rules. Since the years of Röntgen, the threshold of allowable radiation has been reduced by a factor of one million: once 3000 rem per year were considered safe. In Hamburg there is a memorial to the doctors and nurses who were the first to use Xrays in a hospital. Today reactor emissions are mandated to pollute at less than one millionth of that original value. This is less than one-ten thousandth of the value that would immediately cause illness. It is meant to err, if at all, on the safe side, by a very large factor. Thus, technical perfection is required as a precondition. This requirement of approaching the utmost performance possible has its impact upon the safety system: U.S. and West-European reactors are constructed in such a way, that even if several failures were to occur simultaneously the system would still react appropriately (immediate shutdown): This would happen even if human controllers did nothing. And in the remaining rare cases of accidents wouldn't the controller then further increase security with appropriate measures?

One of the surprising lessons learned from the accident at Three Mile Island is that decisions under stress can be so wrong that they markedly increase the risk. Without human eagerness to correct and control the situation at the beginning, the technical equipment would have limited the damage in a much better way. A similar event occured at Brunsbüttel in the Federal Republic of Germany: during an ongoing disturbance, the crew turned off the automatic shutdown so that it could not be triggered. There were two reasons why they did this. First, too many automatic shutdowns would eventually deteriorate the system and the reactor plant would lose its license. Furthermore, every automatic shutdown releases a very small amount of radioactivity. That is no danger, but according to the rigid emission standards, it is only allowed a few times per year. Otherwise, the reactor will lose its 
license. In the case of Brunsbüttel, the controllers thought they could handle the situation without the immediate shutdown. But it was the wrong decision and the damage was much worse than it would have been otherwise. As in the U.S., very clear operating rules will be set for the future.

When we deal with complex systems, stricter rules, more measurement and more technical perfection alone may decrease rather than increase efficiency and safety.

Like a sensitive pet, complex machinery requires special human care. The symbiosis requires us to take into account human factors as well as system peculiarities.

The most expensive and complex system, military command and control systems, may be tested under the most severe circumstances we could imagine. Even under peacetime conditions severe shortcomings have been reported. This is documented, for instance, in reports of the General Accounting Office to the US Congress, e.g.:

Effectiveness of US Forces can be Increased through Improved Weapons systems design, (PSAD-81-17 1/29/81);

Implications of highly sophisticated weapons systems on military capabilities, (PSAD-80-61 6/30/80);

Improving the effectiveness of joint military exercises - an important tool for military readiness, (LCD-80-2 12/11/79);

Attrition in the military - an issue needing management attention, (FPCS-80-10 2/20/80);

Opportunities for further improvement of government logistics management (LCD-80-78 8/21/80);

The readiness of US Air Forces in Europe - selected aspects and issues (this report discusses the need for improved readiness reporting, shortages in certain war reserve material, supply support and maintenance problems, and personal readiness. LSD-18530A 2/16/79).

So far, the cause of all false nuclear alerts can be traced to failures of the human beings in charge. The human factor can contribute significantly to better security, too.

But how safe can security be made on the military level, where extremely complex systems are involved? The modernization of nuclear weapons systems is a good example. Technical progress can lead to greater stability and more security as well as to greater danger and instability. Which will ensue is a matter of political leadership, and follows from straightforward systems considerations.
To illustrate, in the introduction of Polaris, several technical breakthroughs were conceived and carried out all at the same time. Safe underwater handling of atomic weapons and missiles and an effective guidance system were developed and integrated into one system. Thus, a second strike capability was assured.

The technical arguments about the effects of first and second strikes are not just of academic interest. Imagine a Western film in which every person who is shot does not die immediately, but is able to fight back for several days. Of course no one would shoot in the first place and Westerns would then be pretty boring. The whole romance of the common Western is about a second strike of the society, usually carried out by a sheriff, at whatever cost is necessary, even if the entire village is destroyed in a fight against the bad guys.

What may look like a game between good and bad guys in films is analogous to a deadly serious situation among nations in a nuclear war. The recent modernization of nuclear weapons places emphasis on "launch on warnings" and on high accuracy in targeting. This does not affect the superpowers, because any attempt to launch a disarming first strike could fail. Technical progress in antisubmarine warfare might destablilize the situation; however, those who are really nervous about such nervous systems are the Europeans. In regional battlefields on their land, there is a technical necessity to strike:

(a) in time (preemptively, or at least, quickly enough not to be wiped out before launching); and

(b) with sufficient power to limit the counterattack. This leads to rapid uncontrollable escalation. In the interwoven net of mutual attack and defense postures on both sides, the efficiency of any weapon system is almost impossible to predict. The experience of wars in the Middle East or war-like strikes is that technical progress in electronics is rapid on both sides, for attack as well as for defense. Even our best intelligence could not find out what the engineers of the opponent could not know in the first place; there is great uncertainty about the effectiveness of interception of attacks in actual combat.

The International Institute for Strategic Studies in London estimated the efficiency of a counterattack by NATO in Europe. They found that if one third of the approximately 300 starfighters would be assigned a nuclear role, then only six would come through in a counterattack. (The Military Balance 1979-1980, pp. 118-119). Whether any 
one of the six pilots would have a fair chance to find his way back to NATO territory was not studied. Furthermore, the command and control system may not function as it should in a combat situation. This is where the most vital interest of the superpowers would be at stake: it is very hard to keep a complex, triggerprone and vulnerable system under political control. Therefore, it would be very hard to stop escalation to a greater nuclear war. The first steps of a nuclear war may very well come about in the absence of a political decision. For instance, nuclear accidents or false alarms may be the beginning. False alarms in Europe would require political handling in a few minutes rather than within the 15 or 20 minutes available to the U.S.A.

There are complex systems that we hope never to test. Even if several hundred neutron bombs will stop a Soviet tank attack, we should not call that defense: it is a weapon that destroys more at the medical, social and ecological level in home territory than is at stake politically. At Hiroshima, most people who were exposed to radiation succumbed in the initial firestorm. Nonetheless, the amount of longterm damage that has been revealed lately is of surprising magnitude and cruelty. The lives of these survivors is what would be in store for many victims of the neutron bomb (only about $20 \%$ of the people hit in the innermost target area would be dead within a short time). The amount of radioactivity considered "an unavoidable side effect" of nuclear war is a thousand times, for many scenarios even a million times, higher than that allowed for nuclear reactor emissions. Therefore we should look at the nuclear arms race far more critically than at most other hazards. The manifold protests at demonstrations and within the political parties in Europe mostly are not against the U.S.A. Neither the NATO nor a single American soldier is in question. Rather the quantity and quality of atomic weapons works as a selfdeterrent, especially in Germany.

There are no purely technological solutions when further complexity combined with further destructive power increasingly diminishes the hopes for political control and for successful crisis management. Nuclear weapons are an efficient deterrent. But it is the NATO partners of the U.S. in central Europe that are deterred by the recent additional nuclear options of NATO to a far greater extent than the Soviet Union. If this discrepancy of interest within the NATO alliance were detected on the first day of a combat situation, then the alliance could break down on that first day. On the other hand, "if for the United States the security commitment to Europe meant the certain destruction of American cities in the event of war, that commitment would scarcely be given unreservedly" (G. Treverton: Nuclear Weapons in Europe, London IISS, adelphi 168, 1981, p. 27). Therefore, a new joint evaluation of a feasible common defense policy should be carried out by the U.S. and Central Europe. This should be possible, in view of their common culture, common economic system and, last but not least, common engineering attitude toward complex systems.

Philipp SONNTAG 